\title{
OPTIMUM INSPECTION INTERVAL FOR TANKER IN UNIFIED INSPECTION REGIME
}

\author{
Luka GRBIĆ ${ }^{1}$, Jelena ČULIN ${ }^{2^{*}}$, Mirano HESS ${ }^{3}$, Svjetlana HESS ${ }^{4}$ \\ ${ }^{1,2}$ Dept of Maritime, University of Zadar, Croatia \\ ${ }^{3,4}$ Faculty of Maritime Studies, University of Rijeka, Croatia
}

Received 14 June 2018; revised 9 October 2018; accepted 16 December 2018

\begin{abstract}
Inspections on board tankers contribute to the prevention of accidents, which can have a significant impact to humans and environment. Therefore a high amount of tanker inspections is performed by various stakeholders. This practice could be made more efficient by introducing unified inspection regime, which covers existing areas of inspection, eliminates overlapping and has the potential to improve safety. In this paper an important aspect in defining inspection regime, inspection interval, is determined considering contradictory goals: lowering the costs of inspection and increasing useful service life of tanker structure and equipment, without compromising safety. A probabilistic approach has been applied to establish inspection schedule, which fulfils a range of requirements. Due to the many varieties of tanker types, their conditions, range of size and age span, the paper focuses on the 10 years AFRAMAX tanker. Results indicate that optimal inspection interval in the unified inspection regime for that tanker should be 3 months. Using modified input parameters, similar approach could be used for other tanker types.
\end{abstract}

Keywords: oil tanker, tanker inspections, inspection regime, optimum inspection interval, useful service life time, inspection costs, maritime safety.

\section{Notations}

$a$ - crack length;

$a_{0}$ - initial crack length;

$a_{f}$ - critical value of crack length;

$a_{r}$ - critical value of damage intensity for repair;

$a_{t}$ - crack lenght at time $t$;

$C(T)$ - operating cost per unit time;

$C_{k}$ - cost of the breakdown repair;

$C_{p}$ - inspection repair cost;

$\{C\}$ - vector consisting of inspection costs, monitoring costs, detailed inspection costs and repair costs;

$D(T)$ - downtime per unit time;

$E\left(C^{I}\right)$ - expected total cost of inspection;

$E\left(C^{K}\right)$ - expected breakdown cost;

$E(T)$ - expected useful service life of the vessel;

$E\left(T_{\text {ins }}\right)$ - expected inspection interval;

$d_{a}$ - downtime for a breakdown;

$f(h)$ - probability density function;

$h$ - delay-time;

$I_{c}$ - inspection cost;

$k_{r}$ - expected number of breakdowns per unit time;

$L$ - material constant;
$N$ - number of cycles, associated with the stress range;

$N_{a v}$ - annual average number of cycles;

$N_{n}$ - number of interventions;

$P_{k}(T)$ - probability of a fault arising as a breakdown;

$P o D$ - probability that a certain degree of damage will be detected;

$R_{t_{n}}$ - reduction factor which depends on monitoring period $t_{m d}$

$t_{0}$ - initial service life;

$t_{i}$ - time of inspection;

$t_{m d}-$ monitoring period;

$t_{n, i}$ - monitoring time related to intervention $i$, and it is zero in the case of the inspection;

$T$ - service life;

$T_{\text {ins }}$ - inspection interval;

$\left\{t_{i}\right\}$ - vector consisting of design variables of inspection times;

$\left\{t_{n, i}\right\}$ - vector consisting of monitoring durations;

$V$ - material exponent;

$Y(a)$ - geometry function;

${ }^{*}$ Corresponding author. E-mail: jculin@unizd.hr

\#Editor of the TRANSPORT - the manuscript was handled by one of the Associate Editors, who made all decisions related to the manuscript (including the choice of referees and the ultimate decision on the revision and publishing). 
$\alpha$ - shape parameter;

$\alpha_{\delta}-$ quality of inspection (higher quality inspection has a lower value);

$\beta$ - location parameter;

$\beta_{\delta}$ - equal $-0.1 \cdot \ln \left(\alpha_{\delta}\right) ;$

$\delta$ - degree of damage intensity (type, size and shape);

$\delta_{\min }-$ minimum detectable damage intensity;

$\delta_{t o l}-$ upper limit of permissible damage;

$\varphi$ - downtime for inspection;

$\Phi$ - cumulative distribution function;

$\mu$ - scale parameter;

$\vartheta$ - stress range;

$\{\alpha\},\{\beta\}$ - vectors consisting of probability of damage detection function for different inspection and monitoring methods.

\section{Introduction}

Accidents involving tankers can result in considerable environmental damages, socio-economic losses, cleanup costs, research costs and other costs (Liu, Wirtz 2006; Paulauskas 2009). Therefore, an importance of efficiently implemented measures to prevent such accidents has been recognised by ship owners, flag states, port states, classification societies, insurance companies and cargo owners and research results show that safety qualities are the best for this ship type (Knapp, Heij 2017). One of the significant steps to ensure safe tanker operation are inspections. However, the lack of trust between various stakeholders resulted in numerous inspections that are performed on tankers (Knapp, Franses 2010). Namely, 13 mandatory and non-mandatory inspections, surveys and audits have been developed and due to significant overlapping, duration, and frequency they can cause psychophysical strain of the crew, consequently contribute to the occurrence of human error and hence defeat the purpose for which they were introduced (Bielić et al. 2017). Furthermore, total inspection costs per tanker per year are significantly higher than for other ship types (Knapp, Franses 2010).

With motivation to reduce burden to the crew and cut down costs paid by tanker owners, without compromising safety, a thorough analysis of tanker inspection regimes and an investigation of seafarers' experiences and attitudes regarding inspections had been performed, and new, unified inspection regime has been designed (Bielić et al. 2017; Grbić et al. 2018). Briefly, the proposed inspection method unites components of all inspection regimes and reduces the total number of 1685 components inspected annually to 529 . In addition, contrary to the present practice, it is suggested that inspections are performed by two inspectors, one with nautical and one with engineering background. Namely, inspector background influences outcomes of the inspection and appointment of two-member team can increase probability of finding deficiencies (Graziano et al. 2018).
To ensure safe operation, the tanker must be carefully monitored and, if necessary, repaired. The costs of these activities represent, along with the cost of the crew and the fuel, the basic operational costs of the ship. Therefore, a detailed and precise planning of maintenance, repair, or replacement of ship parts and equipment is one of the key factors for achieving optimum ship operations. Since they are important part of the ship maintenance, the selection of proper inspection and monitoring activities plays an important role in optimizing service life and performance (Frangopol 2011).

The aim of this paper is to determine optimal inspection interval of the unified inspection regime for the concerning parties, relating to maintenance, reliability of damage detection, useful service life and associated costs. Presently the practice of carrying out the inspections is that each inspection regime, mostly independently of each other, visits the ship in a port suitable for them (Bielić et al. 2017). Due to a short stay of tankers in ports nowadays, and often situation where two or more inspections' regimes visit the ship in the same (and almost each) port, there is additional work pressure on ship's crew compromising safe ship's operations (Grbić et al. 2018).

Since the international legislations, as well as flag and coast state safety requirements are more and more stringent, thus extending the time needed to pass an increasing number of the inspection items, a further increase in the inspection and maintenance costs is inevitable.

The objective of this research is to ascertain the methodology to harmonize the inspections and eventually reduce visits of inspectors to the ship by determination of optimal inspection interval. Implementation of inspections by recognized inspectors in the proposed interval could harmonize sharing and recognising inspection results among various stakeholders/regimes, reduce the number and duration of inspections and hence reduce the inspection costs and the workload of the ships' crew. It would also help ships' operators in making key maintenance decisions, thus contributing to tankers' safety regime. Some recommendations on how to improve tanker safety are given.

Due to the many varieties of tanker types, their conditions, range of size and age span, a specific tanker in the unified inspection regime has been taken into consideration. Therefore, it should be stressed here that the wording "unified" refers to the inspection regime and not to all possible tanker types. This paper focuses on the low risk, 10 years old AFRAMAX tanker. However, similar methodology could be used for other tanker types.

The paper is organised as follows. A background (first section) provides previous research information on determining inspection interval considering safety and inspection costs. An inspection planning considering tanker useful service life is presented in the second section. The third and the fourth section analyse inspection planning applied to hydraulic deck crane and side plank, respectfully. Conclusions are presented in the last section. 


\section{Background}

Current inspection regimes for tankers include inspections, surveys and audits performed by various stakeholders, such as those of the port and flag states, recognised organisations, insurance companies, cargo owners and ship owners. Among those inspections are (1) port state control, (2) flag state control, (3) annual class survey, (4) insurance survey, (5) vetting inspections, (6) international ship and port facility security code external and internal audits, (7) international safety management code external and internal audits, (8) maritime labour convention external and internal audits, (9) green award survey, and (10) owner's internal technical inspection (Grbić et al. 2018). All of them were introduced in the name of safety, but they are designed according to various motivations and stakeholders' interests (Knapp, Franses 2010). Furthermore, issues in a degree of harmonization and uniformity of inspections performed according to virtually identical legal texts have been identified (Graziano et al. 2017). Therefore, there is a common practice that available findings and results obtained by certain subject in industry are not acknowledged by another. For example, vetting inspection regimes do not recognize inspections, which were performed in another regime, or additional vetting inspections are required by cargo owners.

Inspections vary in content, frequency, length, legal requirement and consequences (Ventikos et al. 2018) and due to duration and frequency may have a detrimental effect on crew members (Knapp, Franses 2010). Sharing of information about inspection results among inspection sources has been proposed to improve inspection effectiveness (Heij et al. 2011; Knapp, Franses 2010). However, an overview and analyses of the inspected components and annual frequency of aforementioned 13 inspection regimes revealed that there is a significant overlapping among them (Bielić et al. 2017). Therefore, there is an opportunity to decrease the number of inspections performed currently and possibly improve inspection efficiency by introducing unified inspection regime. A content of unified inspection (Grbić et al. 2018) has been created based on comparison among existing regimes, analyses of existing problems and with help of experts, as described previously (Bielić et al. 2017).

To determine optimal inspection interval several aspects have to be taken account of. Lowering of the number of inspections should not jeopardize safety. Therefore the annual number of components inspected during proposed unified method should be the same or higher in comparison to present situation. As shown by Bielić et al. (2017) in order to increase the annual number of components inspected and consequently contribute to safety, the inspection interval for the unified regime, $T_{i n s}$ should be less than 3.76 months.

An additional condition must be fulfilled in order to ensure acceptance of the new inspection regime by stakeholders. The total yearly inspection costs per tanker should be less than current. The number and costs of inspections depend on many factors including ship particulars and results of previous inspections. Tanker fleet is relatively young, flies white-listed flags and is associated with the International Association of Classification Societies (IACS, $h t t p: / / w w w$.iacs.org.uk) class (Knapp, Van de Velden 2011).

One more aspect of inspection regime should be considered to select $T_{i n s}$. The survey that has been performed, which included responses from 104 deck and engineer officers (Bielić et al. 2017), showed that $55 \%$ of seafarers think that inspections positively influence work motivation of their colleagues, and $97 \%$ think that such effect lasts one month after the inspection or until the end of their contract. Furthermore, some of them claim that without inspection performed by third party they would not perform all their duties considering monitoring tanker equipment and structure fully, especially if they feel that some of those surveys are obsolete. However, tanker is a complex system and each crew member is responsible for a specific element. Therefore, these results indicate that there is a small, but considering possible consequences, significant possibility that if inspection is not executed during duration of crew members' contract, certain part of ship would not be inspected. Publicly available data from 20 tanker companies were obtained and an average contract duration is estimated to be four months. Therefore, regarding this issue, $T_{i n s}$ should be less than 4 months, which is close to before stated figure.

Based on publicly available data and data obtained from sources of the tanker company, current cost of all inspections, for the low risk, 10 years old AFRAMAX tanker, is estimated to be 33600 USD per year (Grbić et al. 2018). As per expert judgment, estimated cost of the proposed inspection method in Bielić et al. (2017) and Grbić et al. (2018) is 6040 USD per inspection. Thus, the expression $\frac{12}{T_{i n s}} \cdot 6040$ USD $\leq 33600$ USD implies that $T_{\text {ins }}$ should be more or equal than 2.16 months.

From the aforementioned, considering safety and inspection costs paid by tanker owners annually it is indicated that inspection interval should be in interval between 2.16 and 3.76 months.

To define inspection interval, which would be optimal regarding not just safety and costs, but also regarding tanker maintenance a panel of ten experts was carefully selected to provide information needed to perform simulations described in further text. The panel consisted of five experts from tanker companies and five from ship building companies.

\section{Inspection planning considering useful service life of tankers}

Corrosion and fatigue of materials represent the main causes of ship deterioration (Frangopol, Soliman 2013). Therefore, various experimental and theoretical approaches have been proposed to model the optimal methodology of inspection, maintenance and related costs for systems 
subjected to wear and deterioration (Chung et al. 2006; Kim, Frangopol 2011b, 2012; Šelih et al. 2008). However, there are numerous models due to variety of demands and the baseline complications (Ahmad 2003).

An effective inspection enables timely detection of ship structure damages. The degree of damage intensity (type, size and shape) determines the type of maintenance action (Kim, Frangopol 2011b). In the case, the value of $\delta$ is less than $\delta_{t o l}$ there will not be maintenance activities. The value of $\delta_{t o l}$ is determined on the basis of manufacturer's instructions, recommendations, standards, or expert judgment. Values of $\delta$ range from 0 to 1 .

The probability that a certain degree of damage (Frangopol et al. 1997) will be detected is:

$$
\begin{aligned}
& P o D=0 \\
& \text { for } 0 \leq \delta \leq \delta_{\text {min }}
\end{aligned}
$$

and

$$
\text { PoD }=1-\Phi\left(\frac{\ln (\delta)-\ln \left(\alpha_{\delta}\right)}{\beta_{\delta}}\right)
$$

for $\delta>\delta_{\min }$.

Inspection planning can be defined as an optimization problem, maximizing mean of the service life $E(T)$ (Kim et al. 2013). That means, with the given probability density function $f(h)$ of $T, \alpha_{\delta}$ and $\delta$, find $T_{i n s}$, with the objective to maximize $E(T)$. In this model formulation, $T$ is service life, $T_{i n s}$ inspection interval in months, $\alpha_{\delta}$ quality of inspection and $\delta$ damage intensity. Since the damage occurrence and propagation, damage detection and maintenance effect on the service life are subject to uncertainties, the service life is not deterministic. Therefore, $T$ is treated as a random variable.

The optimization results, obtained by MATLAB R2013 (https://www.mathworks.com) optimization tool, are shown in Table 1. The impact of the quality or method of inspection and the intensity of the damage at the inspection interval and useful service life of the tanker is noteworthy.

For example, in case the quality of inspection is 0.1 and the damage intensity is 0.5 , the optimal inspection interval is 2.6 months and the expected useful service life is 26.2 years. By lowering the inspection quality from 0.1

Table 1. Quality of inspection and damage intensity associated with inspection interval and useful service life

\begin{tabular}{|c|l|c|c|c|}
\hline Damage & \multirow{2}{*}{$\begin{array}{c}\text { Inspection interval } \\
\text { intensity } \\
\delta\end{array}$} & \begin{tabular}{c}
$T_{\text {ins }} \begin{array}{c}\text { and useful service } \\
\text { life } E(T)\end{array}$ \\
\cline { 3 - 5 }
\end{tabular} & \multicolumn{3}{|c|}{ Quality of inspection $\alpha_{\delta}$} \\
\hline \multirow{2}{*}{0.0} & $T_{\text {ins }}$ [months] & 2.3 & 0.4 & 0.6 \\
\cline { 2 - 5 } & $E(T)$ [years] & 29.3 & 27.4 & 4.2 \\
\hline \multirow{2}{*}{0.5} & $T_{\text {ins }}$ [months] & 2.6 & 3.0 & 4.0 \\
\cline { 2 - 5 } & $E(T)$ [years] & 26.2 & 23.1 & 22.8 \\
\hline \multirow{2}{*}{1.0} & $T_{\text {ins }}$ [months] & 2.7 & 3.3 & 3.9 \\
\cline { 2 - 5 } & $E(T)$ [years] & 25.2 & 22.1 & 20.5 \\
\hline
\end{tabular}

to 0.4 for the same damage intensity of 0.5 , the expected life time of the tanker is reduced to 23.1 years. The results confirm that the quality or method of inspection affects the inspection interval and useful service life. It is evident that the inspection interval stays in the range of $2.3 \ldots 4.2$ months irrespective of the inspection quality and damage intensity. The higher the quality of inspection, the lower inspection interval and the higher useful service life of the tanker. Besides, the higher the damage intensity, the lower useful service life. Obtained inspection intervals coincide with the optimal inspection intervals from the aspects of the costs and safety.

\section{Inspection planning considering damage detection: hydraulic deck crane case study}

Timely detection and repair of damage to the hydraulic engine of the deck crane will prevent significant costs and serious pollution of the environment resulting from possible oil leakage. To determine optimal inspection interval considering damage detection, a delay-time model under assumptions valid for the simplest non-trivial inspection maintenance problem has been used (Christer, Waller 1984). Briefly, according to the delay-time concept, for every fault there is the delay-time, the time lapse from when a presence of a fault might reasonably be expected to be noticed until the time when failure occurs. The delaytime is described by a probability density function:

$$
f(h)=\frac{\alpha}{\mu} \cdot\left(\frac{h}{\mu}\right)^{\alpha-1} \cdot \exp \left(-\left(\frac{h}{\mu}\right)^{\alpha}\right) .
$$

The probability of a fault arising as a breakdown is:

$$
P_{k}(T)=\int_{0}^{T} \frac{T-h}{T} \cdot f(h) \mathrm{d} h .
$$

Delay-time analysis establishes relationship between $T$ and $D(T)$ or $C(T)$ and enables minimising them.

Downtime per unit time is:

$$
D(T)=\frac{\varphi+k_{r} \cdot T \cdot P_{k}(T) \cdot d_{a}}{T+\varphi} .
$$

Expected cost per unit time is:

$$
C(T)=\frac{k_{r} \cdot T \cdot\left(C_{k} \cdot P_{k}(T)+C_{p} \cdot\left(1-P_{k}(T)\right)\right)+I_{c}}{T+\varphi} .
$$

Input data for delay-time analysis were obtained from various published reports, paper by Cunningham et al. (2011) and experts. Input data were: shape $\alpha=9$, scale $\mu=0.5$, inspection cost $I_{c}=150 \mathrm{USD}$, inspection repair cost $C_{p}=2400 \mathrm{USD}$, cost of the breakdown repair $C_{k}=40200$ USD, expected number of breakdowns per unit time $k_{r}=1411 / 10^{6} \mathrm{~h}$, downtime for inspection $\varphi=$ $14 \mathrm{~min}$, and downtime for a breakdown $d_{a}=59 \mathrm{~h}$. According to the experts, possible inspection intervals vary from 0.5 to 12 months, at intervals of half a month. Figure 1 shows that optimal inspection interval considering costs is 4.5 months, while optimal inspection interval considering downtime is 2.5 months. 


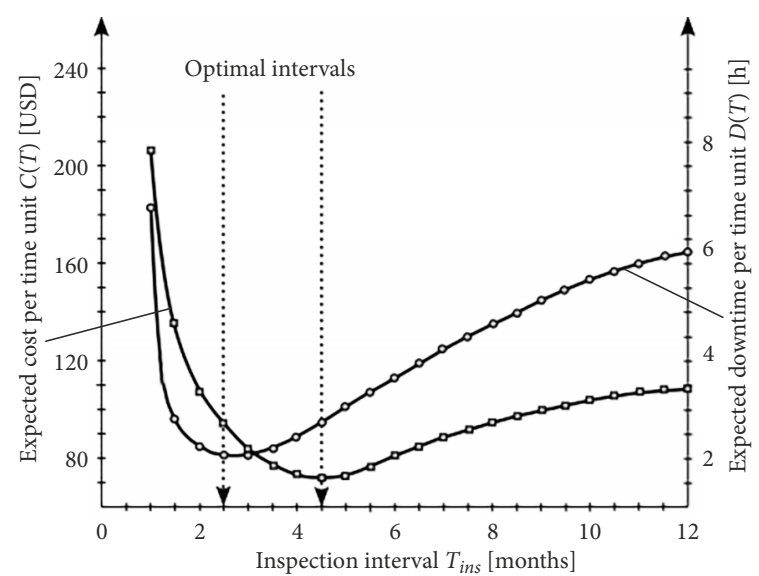

Figure 1. Downtime and costs $v s$ inspection intervals

Therefore, the Analytic Hierarchy Process (AHP) was used to determine weighting factors, and Preference Ranking Organisation METHod for Enrichment Evaluations (PROMETHEE) - for finding the optimal solution. Obtained optimal inspection interval is 3 months, followed by 2.5 and 3.5 months. The worst inspection interval is 1 month. These results are in accordance with optimal inspection interval considering costs and safety.

\section{Inspection planning considering optimum balance of costs and useful service life: side plank case study}

To additionally verify proposed inspection interval, an inspection of side plank structure (Figure 2) has been analysed. This part of the tanker has been selected because it is subjected to fatigue due to torsional forces, cargo transfer and corrosion and it can be expected that at some point crack will occur.

To predict crack length Paris' equation (Paris, Erdogan 1963) was used. A number of cycles associated with the stress range, which shows as a growth in the crack size from an initial size of $a_{0}$ to a size of $a_{t}$ can be calculated as:

$$
N=\frac{1}{L \cdot \vartheta^{V}} \cdot \int_{a_{0}}^{a_{t}} \frac{1}{(Y(a) \cdot \sqrt{\pi \cdot a})^{V}} \mathrm{~d} a .
$$

The number of cycles to failure (i.e., when the damage reaches its critical value $a_{f}$ ) can be obtained by substituting $a_{t}$ by $a_{f}$. The geometry function is assumed to be one. Descriptors of variables in Equation (7) are given in Table 2. The critical value of crack length is assumed to be $70 \mathrm{~mm}$, and useful service life 20 years. Monte Carlo simulation with $10^{7}$ samples was used to predict the crack length over time.

Inspection method to detect and measure crack is assumed to be ultrasonic inspection, with parameters $\alpha$ and $\beta$ are 0.122 and -0.305 , respectively (Forsyth, Fahr 1998). The acoustic emission method is assumed to be used for monitoring. The assumed monitoring periods are one week, two months and six months, where the inspector or

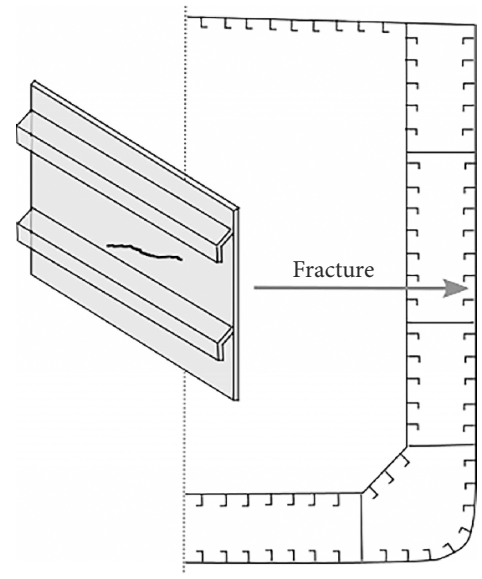

Figure 2. Schematic representation of the analysed structure

expert is responsible for determining the optimal duration with regard to the schedule of planned monitoring tasks.

A probability of detection by acoustic emission is:

$$
P o D=1-\Phi\left(\frac{\ln (a)-\alpha}{\beta}\right) \cdot R_{t_{n}},
$$

where: $\alpha$ and $\beta$ for six months are 0.914 and -0.397 , respectively (Pollock 2007) and is reduction factor, which depends on monitoring period $t_{m d}$. For duration of monitoring of two months and one week $R_{t_{n}}$ are 0.48 and 0.4, respectively.

The inspection planning is formulated as an optimization problem (Kim, Frangopol 2011b):

with known $N_{n},\{C\},\{\alpha\},\{\beta\}$ and probability density function of $t_{0}$ find:

$$
\left\{t_{i}\right\},\left\{t_{n, i}\right\}, a_{r}
$$

such that $t_{i}-t_{i-1} \geq 1.0$ month,

to minimize expected total (inspection, monitoring and maintenance) cost of inspection $E\left(C^{I}\right)$ and expected breakdown cost $E\left(C^{K}\right)$ and maximise expected inspection interval $E\left(T_{i n s}\right)$, where $\left\{t_{i}\right\}$ is the vector consisting of design variables of inspection times; $\left\{t_{n, i}\right\}$ is the vector consisting of monitoring durations; $t_{n, i}$ is monitoring time related to intervention $i$, and it is zero in the case of the inspection; $t_{0}$ is initial service life; $a_{r}$ is critical value of damage intensity for repair; $N_{n}$ is the number of interventions; $\{C\}$

Table 2. Variables for Equation (7)

(Ahmad 2003; Kim, Frangopol 2011a, 2012)

\begin{tabular}{|l|c|c|l|}
\hline Notation [units] & Mean & $\begin{array}{c}\text { Coefficient } \\
\text { of variation }\end{array}$ & $\begin{array}{c}\text { Type } \\
\text { of distribution }\end{array}$ \\
\hline$V[-]$ & 3 & - & deterministic \\
\hline$a_{0}[\mathrm{~mm}]$ & 0.5 & 0.1 & lognormal \\
\hline$L[-]$ & $2.3 \cdot 10^{-12}$ & 0.3 & lognormal \\
\hline$N_{a v}[\mathrm{cycles} /$ years $]$ & $1.0 \cdot 10^{6}$ & 0.1 & lognormal \\
\hline$\vartheta[\mathrm{MPa}]$ & 18 & 0.2 & Weibull \\
\hline
\end{tabular}


is the vector consisting of inspection costs, monitoring costs, detailed inspection costs and repair costs; $\{\alpha\},\{\beta\}$ are vectors consisting of probability of damage detection function for different inspection and monitoring methods. In this example, cost of the inspection is estimated to 900 USD, cost of the monitoring consists initial cost of 900 USD plus additional costs that increase by increasing the monitoring period (400 USD/month). It is assumed that cost of detailed inspection is 2200 USD, maintenance cost is 3800 USD and breakdown cost is 7800 USD. The optimization toolbox, provided in MATLAB R2013, is used. Through the genetic algorithm process with 200 generations and population size 300, a Pareto optimal set is obtained (Figure 3). Design variables and objectives for three maintenance action plans A, B and C, shown in Figure 3 are given in Table 3.

Plans A and B include monitoring by acoustic emission with a duration of two months for each inspection, while Plan C includes only ultrasound inspections. Other solutions, which are not shown, enable application of different detection/monitoring methods. All three plans are characterized by low expected breakdown costs, but show a range of expected costs of maintenance actions and a compromise between them.

In order for a tanker owner or other decision maker to determine the optimal inspection plan with respect to the contradictory goals, first a suitable limits for two of the

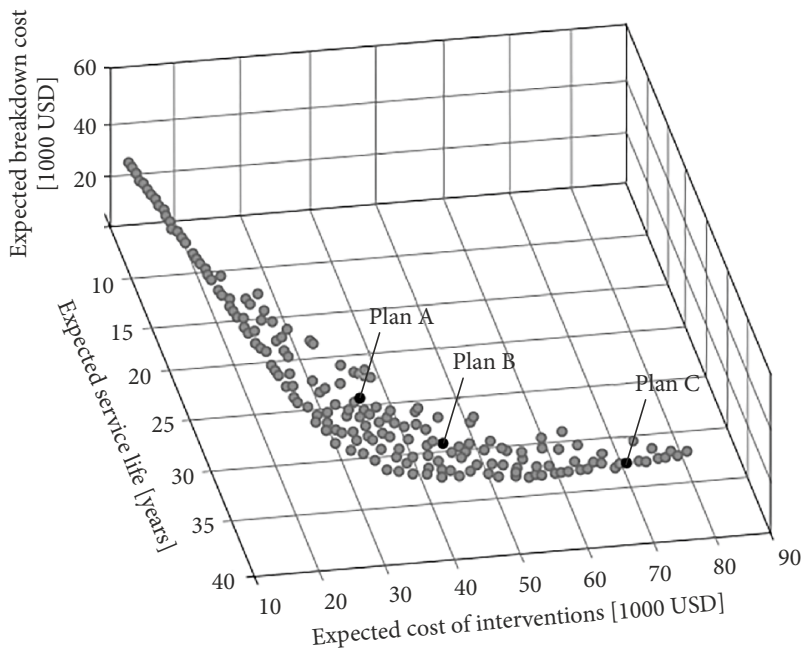

Figure 3. Pareto solution set with objectives to minimize expected total inspection cost and expected breakdown cost and maximise expected inspection interval three goals must be selected and Pareto Front will give a management plan that minimizes the third goal. Although it is not possible to maximize the expected service life and/or maximize inspection interval at the same time with the minimization of expected total cost of inspection and minimization of expected breakdown cost, the method exhibit the variety of inspection intervals, expected inspection costs and expected service life that can be taken, and the compromise between them. For example, a decision maker can set the desired useful service life and acceptable breakdown cost threshold, and Pareto Front will give minimal repair costs and the associated management plan.

The proposed approach helps in establishing the optimal solution and efficient tanker management's decision in the respect of inspection and maintenance segment, ensuring compromises between the contradictory criteria.

\section{Conclusions}

Problems with high level of inspections on board tankers and its potential detrimental consequences have been widely recognized in industry. Nowadays each inspection regime, mostly independently of each other, visits the tanker ship in a suitable port. Consequently, there are often situations where two or more inspections' regimes visit the ship in the same port. Moreover, due to the ever expanding requirements of flag state, coast state and international legislations there is more and more time needed to pass all the inspection items, thus making the regimes visit tankers at almost each port enroute. This practise reflects in the additional work pressure on the ship's crew compromising safe ship's operations, and further increase the inspection and maintenance costs.

Previous researches indicated that inspection interval should be between 2.16 and 3.76 months in order to improve safety while lowering costs paid by the tanker owners.

The originality of this research is in the methodology used, and in solving of the problem of determination of the optimum inspection interval. With the focus on the 10 years old AFRAMAX tanker, this study defined unified inspection regime, by determining the optimum inspection interval, taking into account ship maintenance, damage detection, inspection costs and useful service life of the tanker. Furthermore, case studies of a side plank and a hydraulic deck crane were selected to exemplify the optimum inspection interval.

Table 3. Three optimal inspection plans of multi-objective optimization problem

\begin{tabular}{|c|c|c|c|c|c|c|c|}
\hline \multirow{2}{*}{ Plan } & \multicolumn{4}{|c|}{ Design variables } & \multicolumn{3}{c|}{ Objectives } \\
\cline { 2 - 8 } & $\begin{array}{c}T_{\text {ins1 }}{ }^{*} \\
{[\mathrm{months}]}\end{array}$ & $\begin{array}{c}T_{\text {ins2 }}{ }^{*} \\
{[\mathrm{mon} \text { ths }]}\end{array}$ & $\begin{array}{c}T_{\text {ins3 }}{ }^{*} \\
{[\mathrm{months}]}\end{array}$ & $\begin{array}{c}a_{r} \\
{[\mathrm{~mm}]}\end{array}$ & $\begin{array}{c}E(T) \\
{[\mathrm{months}]}\end{array}$ & $\begin{array}{c}E\left(C^{I}\right) \\
{[\mathrm{USD}]}\end{array}$ & $\begin{array}{c}E\left(C^{K}\right) \\
{[\mathrm{USD}]}\end{array}$ \\
\hline $\mathrm{A}$ & 0.5 & 2 & 11 & 34.4 & 72.3 & 620 & 78400 \\
\hline B & 1.5 & 3 & 9 & 38.6 & 62.0 & 1,406 & 11,050 \\
\hline C & 3 & 4 & 13 & 44.5 & 93.1 & 2,720 & 87205 \\
\hline
\end{tabular}

Note: ${ }^{*}$ - time approximated to 0.5 months. 
Although somewhat expected, the optimization results pointed out that the quality or method of inspection affects the inspection interval and useful service life of the tanker. Furthermore, the results stipulate that regardless of the inspection quality and damage intensity, the inspection interval should be in the range of 2.3...4.2 months. However, the higher the quality of inspection, the lower inspection interval and the higher useful service life of the tanker.

Taking that possible inspection intervals vary from 0.5 to 12 months, at intervals of half a month, and considering the inspection cost and the breakdown repair costs, the case study of damage detection of the hydraulic deck crane indicates that the optimal inspection interval is 3 months.

The optimization problem with three criteria (side plank case study) set to determine the optimal inspection interval and useful service life while minimizing inspection costs and minimizing expected cost of failure has been solved. The decision maker can choose the optimal inspection/maintenance management plan according to the company's policy. Thus, the methodology may serve as a basis for setting an inspection schedule tailored for specific requirements.

Carrying out inspections in the proposed interval could harmonize sharing and recognizing inspection data/results among interested subjects and inspections' regimes, reduce the number and/or duration of inspections and hence reduce the workload of the ships' crew. If it is performed on the basis of the similar criteria by inspectors after standardized training and appointed by recognized organizations it could help to diminish another problem, i.e., lack of uniform application and consequently contribute to the improvement of tanker safety regime. Ship owners may use proposed inspection method to improve their maintenance planning.

Although, as stated earlier, there is no "one size fits all" model because of the complexity of influencing factors and the uncertainty of the baseline parameters, similar approach could be used for other tanker types in a future research.

\section{Author contributions}

Luka Grbić developed initial paper subject, defined the real-life problem, collected and assisted in data analysis, and was responsible for model design.

Jelena Čulin was responsible for model design and development, interpreted the model output and wrote concluding remarks.

Mirano Hess wrote the first draft of the paper and made interpretation of data.

Svjetlana Hess thoroughly rehearsed and analysed the data.

\section{Disclosure statement}

The authors declare that they have no competing financial, professional, or personal interests.

\section{References}

Ahmad, S. 2003. Reinforcement corrosion in concrete structures, its monitoring and service life prediction - a review, Cement and Concrete Composites 25(4-5): 459-471.

https://doi.org/10.1016/S0958-9465(02)00086-0

Bielić, T.; Hess, M.; Grbić, L. 2017. Unified tanker survey and inspection regime in terms of reducing psychophysical strain of the crew, Promet - Traffic \& Transportation 29(4): 455-461. https://doi.org/10.7307/ptt.v29i4.2362

Christer, A. H.; Waller, W. M. 1984. Delay time models of industrial inspection maintenance problems, Journal of the Operational Research Society 35(5): 401-406.

https://doi.org/10.1057/jors.1984.80

Chung, H.-Y.; Manuel, L.; Frank, K. H. 2006. Optimal inspection scheduling of steel bridges using nondestructive testing techniques, Journal of Bridge Engineering 11(3): 305-319. https://doi.org/10.1061/(ASCE)1084-0702(2006)11:3(305)

Cunningham, A.; Wang, W.; Zio, E.; Wall, A.; Allanson, D.; Wang, J. 2011. Application of delay-time analysis via Monte Carlo simulation, Journal of Marine Engineering \& Technology 10(3): $57-72$.

https://doi.org/10.1080/20464177.2011.11020252

Forsyth, D. S.; Fahr, A. 1998. An evaluation of probability of detection statistics, in RTO Meeting Proceedings 10: Airframe Inspection Reliability under Field/Depot Conditions, 13-14 May 1998, Brussels, Belgium, 10-1-10-5.

Frangopol, D. M. 2011. Life-cycle performance, management, and optimisation of structural systems under uncertainty: accomplishments and challenges, Structure and Infrastructure Engineering: Maintenance, Management, Life-Cycle Design and Performance 7(6): 389-413.

https://doi.org/10.1080/15732471003594427

Frangopol, D. M.; Lin, K.-Y.; Estes, A. C. 1997. Life-cycle cost design of deteriorating structures, Journal of Structural Engineering 123(10): 1390-1401.

https://doi.org/10.1061/(ASCE)0733-9445(1997)123:10(1390)

Frangopol, D. M.; Soliman, M. 2013. Damage to ship structures under uncertainty: evaluation and prediction, in G. Z. Voyiadjis (Ed.). Handbook of Damage Mechanics, 1-22.

https://doi.org/10.1007/978-1-4614-8968-9_34-1

Graziano, A.; Cariou, P.; Wolff, F.-C.; Mejia, M. Q.; SchröderHinrichs, J.-U. 2018. Port state control inspections in the European Union: do inspector's number and background matter?, Marine Policy 88: 230-241.

https://doi.org/10.1016/j.marpol.2017.11.031

Graziano, A.; Schröder-Hinrichs, J.-U.; Ölcer, A. I. 2017. After 40 years of regional and coordinated ship safety inspections: destination reached or new point of departure?, Ocean Engineering 143: 217-226.

https://doi.org/10.1016/j.oceaneng.2017.06.050

Grbić, L.; Čulin, J.; Bielić, T. 2018. Inspections on board oil tankers: present situation and suggestion for improvement, Scientific Journal of Maritime Research - Multidisciplinarni znanstveni časopis Pomorstvo 32(1): 132-140. https://doi.org/10.31217/p.32.1.13

Heij, C.; Bijwaard, G. E.; Knapp, S. 2011. Ship inspection strategies: effects on maritime safety and environmental protection, Transportation Research Part D: Transport and Environment 16(1): 42-48. https://doi.org/10.1016/j.trd.2010.07.006 
Kim, S.; Frangopol, D. M. 2011a. Inspection and monitoring planning for RC structures based on minimization of expected damage detection delay, Probabilistic Engineering $\mathrm{Me}$ chanics 26(2): 308-320.

https://doi.org/10.1016/j.probengmech.2010.08.009

Kim, S.; Frangopol, D. M. 2011b. Optimum inspection planning for minimizing fatigue damage detection delay of ship hull structures, International Journal of Fatigue 33(3): 448-459. https://doi.org/10.1016/j.ijfatigue.2010.09.018

Kim, S.; Frangopol, D. M. 2012. Probabilistic bicriterion optimum inspection/monitoring planning: applications to naval ships and bridges under fatigue, Structure and Infrastructure Engineering: Maintenance, Management, Life-Cycle Design and Performance 8(10): 912-927. https://doi.org/10.1080/15732479.2011.574811

Kim, S.; Frangopol, D. M.; Soliman, M. 2013. Generalized probabilistic framework for optimum inspection and maintenance planning, Journal of Structural Engineering 139(3): 435-447. https://doi.org/10.1061/(ASCE)ST.1943-541X.0000676

Knapp, S.; Franses, P. H. 2010. Comprehensive review of the maritime safety regimes: present status and recommendations for improvements, Transport Reviews 30(2): 241-270. https://doi.org/10.1080/01441640902985934

Knapp, S.; Heij, C. 2017. Evaluation of total risk exposure and insurance premiums in the maritime industry, Transportation Research Part D: Transport and Environment 54: 321-334. https://doi.org/10.1016/j.trd.2017.06.001

Knapp, S.; Van de Velden, M. 2011. Global ship risk profiles: safety and the marine environment, Transportation Research Part D: Transport and Environment 16(8): 595-603. https://doi.org/10.1016/j.trd.2011.08.001

Liu, X.; Wirtz, K. W. 2006. Total oil spill costs and compensations, Maritime Policy \& Management: the Flagship Journal of International Shipping and Port Research 33(1): 49-60. https://doi.org/10.1080/03088830500513352

Paris, P.; Erdogan, F. 1963. A critical analysis of crack propagation laws, Journal of Basic Engineering 85(4): 528-533. https://doi.org/10.1115/1.3656900

Paulauskas, V. 2009. The safety of tankers and single point mooring during loading operations, Transport 24(1): 54-57. https://doi.org/10.3846/1648-4142.2009.24.54-57

Pollock, A. 2007. Probability of detection for acoustic emission, Journal of Acoustic Emission 25: 231-237.

Šelih, J.; Kne, A.; Srdić, A.; Žura, M. 2008. Multiple-criteria decision support system in highway infrastructure management, Transport 23(4): 299-305. https://doi.org/10.3846/1648-4142.2008.23.299-305

Ventikos, N. P.; Sotiralis, P.; Drakakis, M. 2018. A dynamic model for the hull inspection of ships: the analysis and results, Ocean Engineering 151: 355-365.

https://doi.org/10.1016/j.oceaneng.2017.11.020 